\title{
Whatever you do: Do it cautiously and consider the consequences!
}

\author{
Michael J. Zellweger, $\mathrm{MD}^{\mathrm{a}}$ \\ a Cardiology Department, University Hospital Basel, University of Basel, Basel, Switzerland
}

Received Jul 12, 2021; accepted Jul 13, 2021

doi: 10.1007/s12350-021-02766-9

\section{See related article, pp. 1109-1116}

Quidquid agis, prudenter agas, et respice finem.

Gesta Romanorum

Non-invasive cardiac imaging is widely used as gatekeeper for coronary angiography and revascularization in stable coronary artery disease (CAD)/chronic coronary syndrome. There are plenty of data demonstrating that referral rates to coronary angiography are higher in patients with than in patients without perfusion abnormalities, as assessed by myocardial perfusion SPECT (MPS) and positron emission tomography (PET). Moreover, observational studies reveal that stable CAD patients who undergo direct coronary angiography generate higher diagnostic costs and greater rates of intervention and follow-up costs than patients who first undergo MPS. Of note, the prognosis was not different in the before-mentioned patient groups. ${ }^{1}$

In the seminal propensity-matched retrospective patient cohort study by Hachamovitch et al, revascularization compared with medical therapy provided greater survival benefit in patients with moderate to large amounts of ischemia (myocardial ischemia $>10 \%$ of the total myocardium). ${ }^{2}$

However, the prospective large randomized trials COURAGE, BARI-2D, and ISCHEMIA did not demonstrate a survival benefit of revascularization over medical therapy in stable CAD patients during relatively short follow-up periods. ${ }^{3-5}$ An important point is that a high number of patients randomized to medical therapy in these trials underwent revascularization during the

\footnotetext{
Reprint requests: Michael J. Zellweger, MD, Cardiology Department, University Hospital Basel, University of Basel, Petersgraben 4, 4031 Basel, Switzerland; michael.zellweger@usb.ch

J Nucl Cardiol 2022;29:1117-8.

$1071-3581 / \$ 34.00$

Copyright (C) 2021 American Society of Nuclear Cardiology.
}

follow-up period and thus were cross-over patients $(21 \%, 32 \%$, and $42 \%$ in ISCHEMIA, COURAGE, and BARI-2D, respectively). Unfortunately, no "on treatment analysis" of these studies is available so far. However, in the ISCHEMIA trial, patients assigned to the invasive strategy had better improvement in anginarelated health status than those assigned to the conservative strategy. ${ }^{6}$

Results of a meta-analysis of these three and other similar studies demonstrate a significant reduction of cardiac mortality in favor of coronary revascularization compared with medical therapy alone in stable CAD patients. The survival benefit was directly linked to the duration of the follow-up period and a lower risk of spontaneous myocardial infarction. ${ }^{7}$

Thus, what moves doctors and patients into the direction of invasive evaluation, coronary angiography, and revascularization in stable CAD?

- Symptoms, especially those not improving with medical therapy

- Ischemia as assessed by non-invasive testing, especially if there is a large extent of ischemia $(>10 \%)$

- The opinion/belief that revascularization tackles the problem at the roots

- The hope that after revascularization there is no longer the need for " a lot of medication",

- The opinion that revascularization not only improves symptoms and quality of life but also prognosis

On the other hand, what does doctors keep from referral to and patients from undergoing coronary angiography even with a large extent of ischemia?

The current study by Thomas et al in this Journal confirmed some of the points why patients are referred to coronary angiography, especially those which are linked to the severity of ischemia (e.g., ischemic ECG response, large ischemic burden, transient ischemic dilation, and decreased myocardial blood flow reserve). Thomas et al (current study) showed that the more abnormal the PET result the higher the rate of coronary 
angiography referrals. Patients who underwent coronary angiography had a higher cardio-vascular risk profile than patients who did not undergo coronary angiography.

In patients with ischemia, those with no prior CAD had higher referral rates than those with known CAD; this held true among patients with severe ischemia: $69.4 \%$ and $61.2 \%$, respectively. Overall, these numbers are consistent with $34.5 \%$ of patients with severe ischemia who did not undergo coronary angiography. This mismatch seems to be quite big. With the aim to find out more about this mismatch, and why patients were not referred to coronary angiography, the authors evaluated reasons for the discordance between PET findings and subsequent patient management (e.g., referral to coronary angiography).

In a small random sample of 100 patients with severe ischemia not referred for angiography the authors evaluated reasons for non-referral on a more individual level. Interestingly, the most common physician reason not to refer patients was uncertainty regarding whether test results were responsible for the patient's symptoms, renal failure, and patient age, frailty, or cognitive status, while patient preference for medical management was the most common patient reason.

These results are quite astonishing. Even though an abnormal PET must not necessarily be followed by coronary angiography, since cardiac imaging correlates patient symptoms and findings (e.g., ischemia) and helps to make a diagnosis and to decide if patients need CAD treatment, one would expect higher referral rates. In fact, Thomas et al show that patients received intensified medical therapy after PET. But we do not learn if these are the patients who underwent coronary angiography and modification of therapy or if particularly those patients got intensified medical therapy who didn't undergo coronary angiography?

Nevertheless, if the PET was ordered because of symptoms and the patient had evidence of extensive ischemia-why did physicians think that symptoms were not due to the documented ischemia (19\%)? Did the physicians not trust the test results? On the other hand, severe ischemia was still the most robust predictor of referral to coronary angiography (severe ischemia had an OR of 42 and 22, in patients without and with known $\mathrm{CAD}$, respectively).

The majority of the other non-referral reasons are consistent with competing health risks and comorbidities
(54\%). Most of these factors were and are known before patients are referred to further testing, be it PET, coronary angiography, or whatever.

Even if it is self-evident, before ordering a test we need to ask ourselves what the consequences of a test result for our patients are. Does the test result provide answers to open questions and influence our decisionmaking - and can we integrate it into a holistic diagnostic and therapeutic strategy for our patients?

\section{Disclosure}

Michael J. Zellweger declares that there is no conflict of interest.

\section{References}

1. Shaw LJ, Hachamovitch R, Berman DS, Marwick TH, Lauer MS, Heller GV, et al. The economic consequences of available diagnostic and prognostic strategies for the evaluation of stable angina patients: An observational assessment of the value of precatheterization ischemia. Economics of Noninvasive Diagnosis (END) Multicenter Study Group. J Am Coll Cardiol 1999;33:6619.

2. Hachamovitch R, Hayes SW, Friedman JD, Cohen I, Berman DS. Comparison of the short-term survival benefit associated with revascularization compared with medical therapy in patients with no prior coronary artery disease undergoing stress myocardial perfusion single photon emission computed tomography. Circulation 2003;107:2900-7.

3. Boden WE, O'Rourke RA, Teo KK, Hartigan PM, Maron DJ, Kostuk WJ, et al. Optimal medical therapy with or without PCI for stable coronary disease. N Engl J Med 2007;356:1503-16.

4. Frye RL, August P, Brooks MM, Hardison RM, Kelsey SF, MacGregor JM, et al. A randomized trial of therapies for type 2 diabetes and coronary artery disease. N Engl J Med 2009;360:250315 .

5. Maron DJ, Hochman JS, Reynolds HR, Bangalore S, O'Brien SM, Boden WE, et al. Initial invasive or conservative strategy for stable coronary disease. N Engl J Med 2020;382:1395-407.

6. Spertus JA, Jones PG, Maron DJ, O'Brien SM, Reynolds HR, Rosenberg Y, et al. Health-status outcomes with invasive or conservative care in coronary disease. $N$ Engl $J$ Med 2020;382:1408-19.

7. Navarese EP, Lansky AJ, Kereiakes DJ, Kubica J, Gurbel PA, Gorog DA, et al. Cardiac mortality in patients randomised to elective coronary revascularisation plus medical therapy or medical therapy alone: A systematic review and meta-analysis. Eur Heart J 2021. https://doi.org/10.1093/eurheartj/ehab246.

Publisher's Note Springer Nature remains neutral with regard to jurisdictional claims in published maps and institutional affiliations. 